\title{
General paper \\ CHANGE IN RESIDUAL STRESSES OF TiN FILMS DUE TO ANNEALING TREATMENTS
}

\author{
Tatsuya Matsue*, Takao Hanabusa** and Yasukazu IkeUCHI* \\ * Niihama National College of Technology \\ 7-1 Yagumo-cho Niihama 792-8580, Japan \\ **Faculty of Engineering, Tokushima University \\ 2-1 Jyosanjima-cho Tokushima 770-8506, Japan
}

\begin{abstract}
The structure and residual stresses of TiN films deposited on a steel substrate were investigated by X-ray diffraction. TiN films approximately $4 \mu \mathrm{m}$ thick were deposited on one side of the substrate by thermal chemical vapor deposition ( $\operatorname{TiN}_{\mathrm{CVD}}$ film). The $\operatorname{TiN}_{\mathrm{CVD}}$ film exhibited high $\{100\}$ orientation. The two-exposure method was used to evaluate residual stresses in the TiN films by measuring lattice strains in the directions determined by the crystal orientation of the film. The $\mathrm{TiN}_{\mathrm{CVD}}$ films had the compressive residual stress of $-1.8 \mathrm{GPa}$, which is as large as the thermal residual stress expected from a thermal strain mismatch between the film and the substrate. The residual stresses did not change by annealing at temperatures below $1073 \mathrm{~K}$, but they increased with increasing annealing temperatures above $1073 \mathrm{~K}$, almost along with the thermal residual stresses. By X-ray photoelectron spectroscopy (XPS), we determined the ratio of nitrogen to titanium (N/Ti) after the annealing treatments. The results of the XPS analysis showed that the initial value of N/Ti was about 1.08 in the as-deposited TiN films and that the ratio of $\mathrm{N} / \mathrm{Ti}$ did not change after annealing at temperatures below $1073 \mathrm{~K}$, but decreased to 1.00 after annealing at temperatures above $1073 \mathrm{~K}$.
\end{abstract}

Key words: Titanium nitride, Chemical vapor deposition, X-ray diffraction, X-ray photoelectron spectroscopy, Residual stress, Annealing treatment

\section{INTRODUCTION}

TiN coatings are widely used as a thermal corrosion barrier and a wear resistance. They are usually deposited on steel, e.g. on punching dies and cutting tools, to extend their lives. However, large residual stresses are necessarily enervated in coating films due to mismatch of thermal expansion between the film and the substrate and other reasons [1-3], exerting a great influence on the mechanical properties of coated material. Therefore, it is important to know the state of residual stresses in the film and the substrate.

$\mathrm{X}$-ray stress measurement is very useful to investigate these residual stresses in the coatings. Considerable efforts $[4,5]$ have been made in stress measurement of various ceramic coatings (including TiN), deepening our understanding about the relationship between the residual stress and process parameters such as depositing temperatures.

In the previous paper [6], we found that the residual stresses in the TiN films deposited by the Multi-Arc physical vapor deposition method (TiN $\mathrm{NVD}_{\mathrm{P}}$ film) were changed by annealing. In the present paper, we investigate the stress state in the TiN films deposited by thermal chemical vapor deposition $\left(\mathrm{TiN}_{\mathrm{CVD}}\right.$ film) based on the X-ray stress measuring method. By X-ray photo- electron spectroscopy (XPS), we determined the ratio of nitrogen to titanium (N/Ti) after the annealing. A comparison was made between the residual stresses in the $\mathrm{TiN}_{\mathrm{CVD}}$ and $\mathrm{TiN} \mathrm{N}_{\mathrm{PVD}}$ films and the ratio of $\mathrm{N} / \mathrm{Ti}$ after annealing.

\section{EXPERIMENTAL DETAILS}

\subsection{Materials}

Spring steel (SUP3:JIS) plates measuring $12 \mathrm{~mm} \times$ $20 \mathrm{~mm} \times 4 \mathrm{~mm}$ was used as a substrate. Before deposition the substrate was ground to the surface roughness of $0.05 \mu \mathrm{m} \mathrm{Ra}$, and then annealed for 1 hour at $873 \mathrm{~K}$. Residual stresses of the annealed substrate were ranging from $-5 \mathrm{MPa}$ to $10 \mathrm{MPa}$.

$\mathrm{TiN}_{\mathrm{CVD}}$ and $\mathrm{TiN} \mathrm{NVD}_{\mathrm{PV}}$ films were deposited on one side of the substrate by thermal CVD and Multi Arc

Table 1. Conditions of TiN depositing.

\begin{tabular}{c|c|c|c|c}
\hline $\begin{array}{c}\text { Name of } \\
\text { specimen }\end{array}$ & Film & $\begin{array}{c}\text { Film } \\
\text { thickness } \\
\mu \mathrm{m}\end{array}$ & $\begin{array}{c}\text { Depositing } \\
\text { temperature } \\
\mathrm{K}\end{array}$ & $\begin{array}{c}\text { Coating } \\
\text { method }\end{array}$ \\
\hline TiNPVD & \multirow{2}{*}{ TiN } & 4 & 523 & PVD \\
\cline { 1 - 3 } & & 973 & CVD \\
\hline
\end{tabular}


PVD. The films was approximately $4 \mu \mathrm{m}$ in thickness. Table 1 shows conditions of TiN depositing.

\subsection{X-ray Stress Measuring Method}

As it will be explained in detail in the following, the $\mathrm{TiN}_{\mathrm{CVD}}$ and TiN $\mathrm{N}_{\mathrm{PV}}$ films exhibit high $\{100\}$ and $\{111\}$ orientation, respectively. In such a case, no diffraction intensity appears at any $\psi$ angle except for particular angles $\psi$ defined by the crystal structure combined with crystal orientation. Because the $\sin ^{2} \psi$ method cannot be adopted in this case, residual stresses in the TiN films were evaluated by the two-exposure method with measuring lattice strains in the directions determined by the crystal orientation of the film [6]. When $\{100\}$ plane of the cubic lattice lies parallel to the surface, TiN420 diffraction appears at $\psi_{1}=26.6^{\circ}$ and $\psi_{2}=63.4^{\circ}$. When the $\{111\}$ plane of the cubic lattice lies parallel to the surface, we obtain 222 diffractions at $\psi=0^{\circ}$ and $70.5^{\circ}[6,7]$. In the both cases, $\psi$ is the angle between the normal of the specimen surface and the normal of the diffraction plane. In this case, if we assume an equal-axial plane stress state, the following equation can be used for evaluating residual stress $\sigma$,

$$
\sigma=\frac{E}{1+\nu} \cdot \frac{d_{\psi 1}-d_{\psi 2}}{d_{0}} \cdot \frac{1}{\sin ^{2} \psi_{1}-\sin ^{2} \psi_{2}},
$$

where $E$ and $v$ are Young's modulus (429 $\mathrm{GPa}$ ) and Poisson's ratio $(0.19)$ respectively, these have been calculated from the single-crystal elastic constants of TiN by using the Eshelby-Kröner model [8]. $d_{0}$ is the spacing of the same planes in the absence of stress. $d \psi_{1}$ and $d_{\psi_{2}}$ are the strains calculated by the Bragg low from the $2 \theta$ values of TiN420 and TiN222 diffraction at the above two $\psi$ angles. Table 2 shows X-ray measurement conditions.

\subsection{X-ray Photoelectron Spectroscopy(XPS) Analysis}

The ratio of N/Ti was determined by X-ray photoelectron spectroscopy (XPS) depth profile analysis of Perkin Elmer Phi 1600E [Mgk $\alpha$ ]. The XPS analysis was performed after Ar sputter etching on TiN film surface.

The depth profile of the spectra of $\mathrm{N}-1 s$ and that of Ti- $2 p$ peaks were measured by the XPS analysis. We calculated the ratio of N/Ti by comparing the areas of $\mathrm{N}-1 s$ peak with that of Ti-2p peak after background corrections.

\subsection{Annealing Treatment}

In order to investigate how the structure and the residual stress in the film change by heat-cool cycles, the specimens were annealed in a vacuum furnace at temperatures of $473,673,873,1073,1273$ and $1473 \mathrm{~K}$. The duration of each temperature was 60 minutes. After
Table 2. X-ray measurement conditions.

\begin{tabular}{c|c}
\hline Material & TiN \\
\hline Characteristic X-ray & $\mathrm{CuK} \alpha$ \\
\hline Tube voltage & $40 \mathrm{kV}$ \\
\hline Tube current & $20 \mathrm{~mA}$ \\
\hline X-ray optics & $\begin{array}{c}\text { Para- } \\
\text { forcusing }\end{array}$ \\
\hline Filter & Nickel \\
\hline $\begin{array}{c}\text { Diffraction for } \\
\text { stress mesurement } \\
\text { (20,deg.) }\end{array}$ & $\begin{array}{c}\text { TiN420(CVD) } \\
\text { (108.7) } \\
\text { TiN222(PVD) } \\
(78)\end{array}$ \\
\hline Irradiated area & $2 \times 8 \mathrm{~mm}^{2}$ \\
\hline
\end{tabular}

annealing treatment, specimens were cooled down to the room temperature.

\section{EXPERIMENTAL RESULTS}

\subsection{Crystal Orientation of TiN Film}

Figure 1 shows examples of the X-ray diffraction pattern from the $\mathrm{TiN}_{\mathrm{CVD}}$ film. Because of the high $\{100\}$ orientation of the $\mathrm{TiN}_{\mathrm{CVD}}$ film, only two intensity peaks, 200 and 400 diffraction of $\mathrm{TiN}_{\mathrm{CVD}}$, were detected in $\theta-2 \theta$ scanning for both as-deposited and annealed $\mathrm{TiN}_{\mathrm{CVD}}$ films. The peak intensity of 200 and 400 diffraction did not change by annealing below $1073 \mathrm{~K}$. However, many diffraction peaks including 200 and 400 diffraction appeared after annealing at $1273 \mathrm{~K}$. The intensity of all these peaks from the TiN film decreased

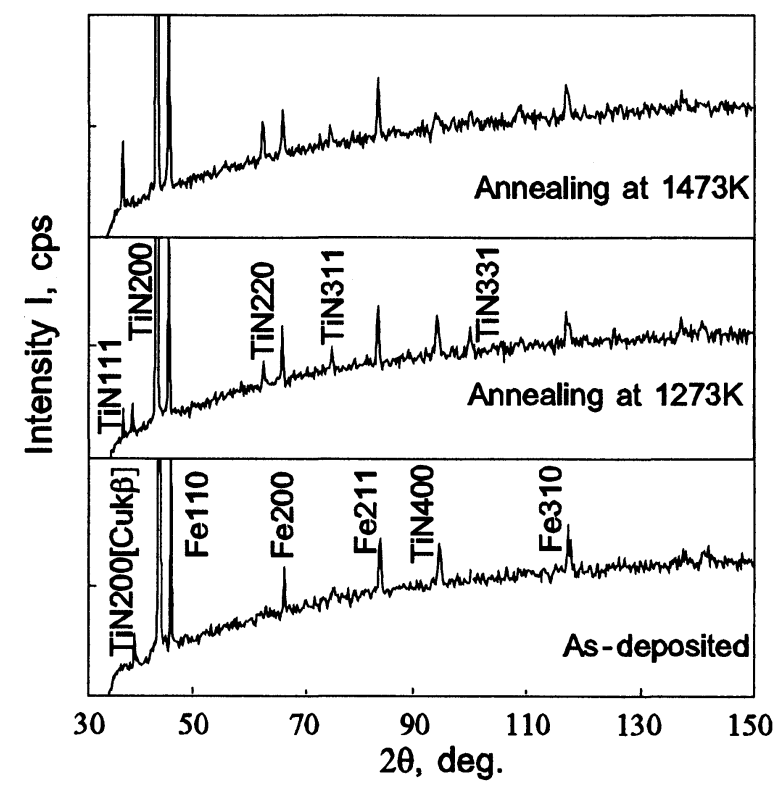

Fig.1. Change in diffraction pattern of $\mathrm{TiN}_{\mathrm{CVD}}$ film with annealing treatment; as-deposited and after annealing at $1273 \mathrm{~K}$ and $1473 \mathrm{~K}$. 


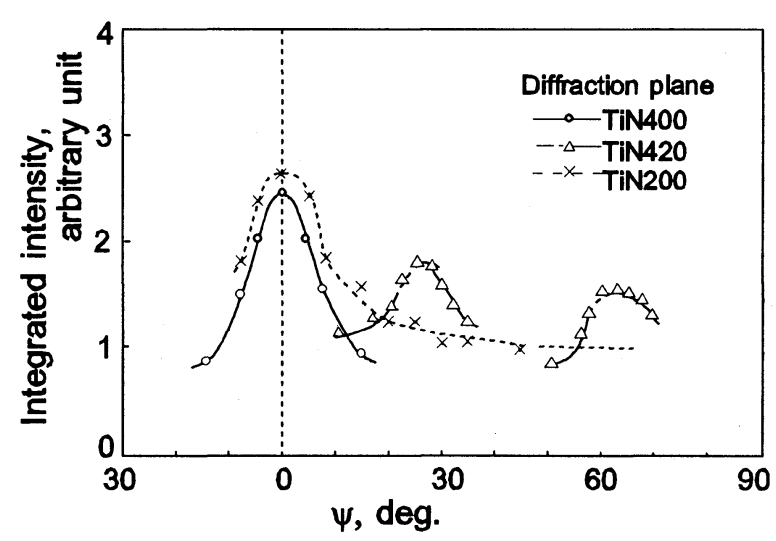

Fig.2. Integrated intensity distribution against $\psi$; asdeposited $\mathrm{TiN}_{\mathrm{CVD}}$ film, TiN200, 400 and 420 diffractions, $\mathrm{CuK} \alpha$ radiation.

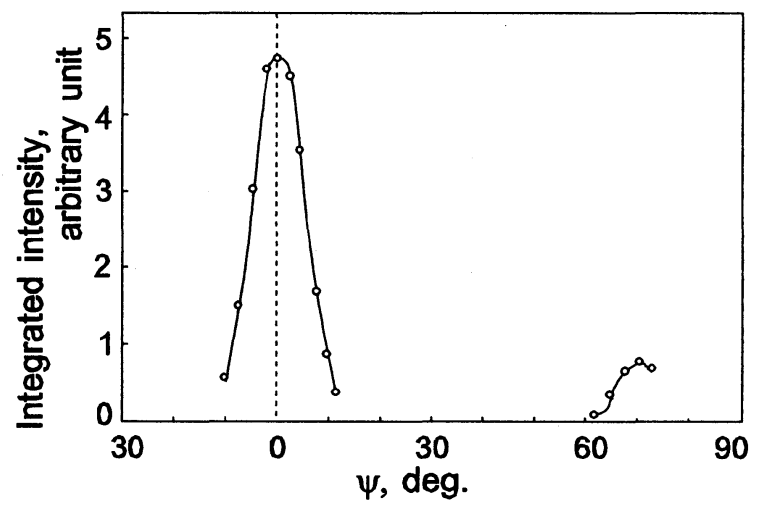

Fig.3. Integrated intensity distribution against $\psi$ angles;

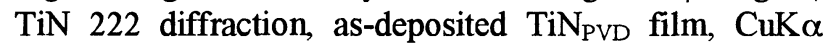
radiation.

after annealing at $1473 \mathrm{~K}$.

When $\{100\}$ plane of the cubic lattice lies parallel to the surface, TiN420 diffraction appears at $\psi=26.6^{\circ}$ and $63.4^{\circ}$. Figure 2 shows the distribution of integrated intensity in the $\mathrm{TiN}_{\mathrm{CVD}}$ film at $\psi$-angles. TiN400 diffraction and TiN420 diffraction appeared within a few degrees around $\psi=00^{\circ}, 27^{\circ}$ and $63^{\circ}$, respectively. The TiN200 shows a peak around $\psi=0^{\circ}$ and a gentle decrease at $\psi$-angles, i.e., small TiN200 diffraction appeared even after a large increase in $\psi$. These results mean that the $\mathrm{TiN}_{\mathrm{CVD}}$ film is mainly composed of $\{100\}$ oriented crystal, i.e., the $\{100\}$ crystal axis of the TiN crystals coincides with the normal of the TiN film surface, but small parts of the crystal are randomly oriented.

On the other hand, in the case of $\mathrm{TiN}_{\mathrm{PVD}}$ film, only two intensity peaks of 111 and 222 diffractions of TiN were detected by $2 \theta$ scanning for both the as-deposited $\mathrm{TiN}_{\text {PVD }}$ film and the annealed $\mathrm{TiN}_{\mathrm{PVD}}$ film. Figure 3 shows the integrated intensity distribution against $\psi$ angles in the $\mathrm{TiN}_{\mathrm{PVD}}$ film. The $\{111\}$ of TiN crystals

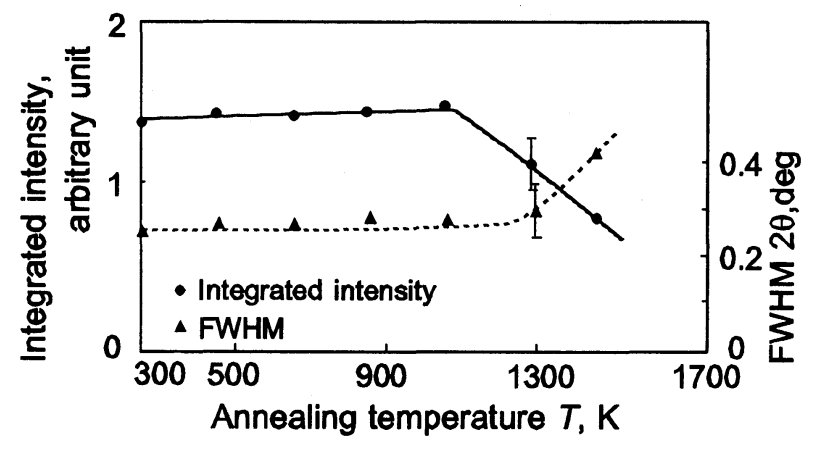

Fig.4. Changes in integrated intensity and FWHM with increasing annealing temperatures, $\mathrm{TiN}_{\mathrm{CVD}}$ film, TiN200 diffraction.

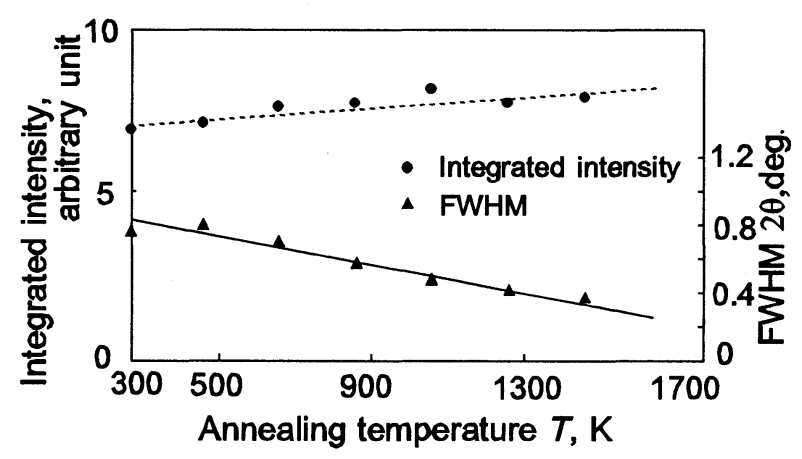

Fig.5. Change in integrated intensities and FWHM with increasing annealing temperature TiN $\mathrm{NVD}_{\text {film, TiN200 }}$ diffraction [6].

orients parallel to the surface normal of the substrate within \pm 10 degrees. These results mean that the TiN $N_{P V D}$ film exhibited high $\{111\}$ orientation.

\subsection{Change in Crystal Structure of TiN Film}

Figure 4 represents the changes in integrated intensity and in the full width at half-maximum intensity (FWHM) by annealing in the $\mathrm{TiN}_{\mathrm{CVD}}$ film. These data were obtained from TiN200 diffraction at $\psi=0^{\circ}$. Each of the points in the figure shows the average value of measurements of five times. For annealing at $1273 \mathrm{~K}$, the measured values scatter largely as shown by the error bar, which represents the range of the measured values. For the other annealing, the scatter was below one order of magnitude. The integrated intensity and the FWHM did not change by annealing below $1073 \mathrm{~K}$. However, a large decrease in the integrated intensity and a large increase in the FWHM were observed after the annealing above $1073 \mathrm{~K}$.

Figure 5 was obtained from 222 diffraction of $\mathrm{TiN}_{\mathrm{PVD}}$ film. A small increase in the integrated intensity and a relatively large decrease in the FWHM were 


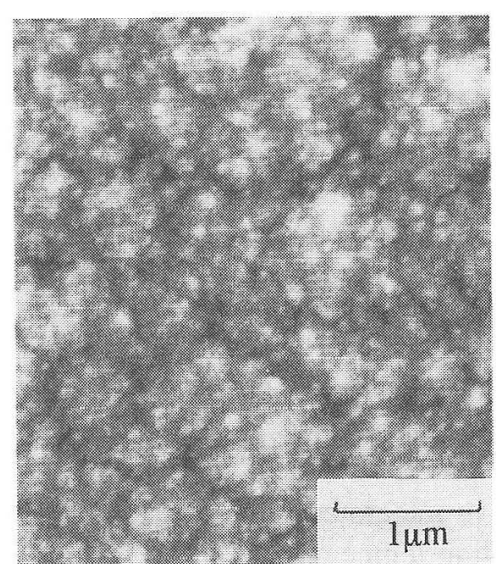

(a) as-deposited

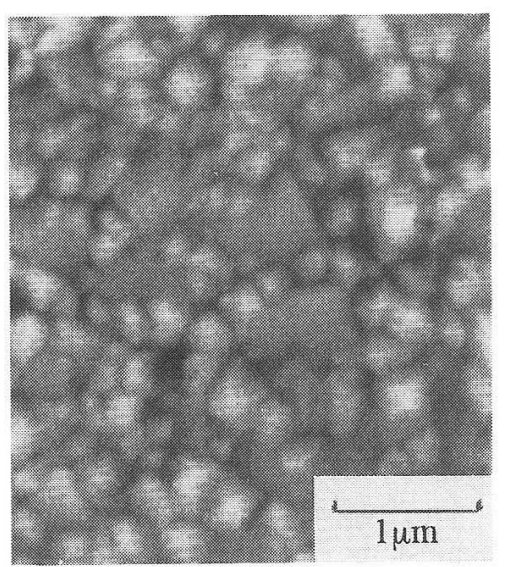

(b) $1073 \mathrm{~K}$

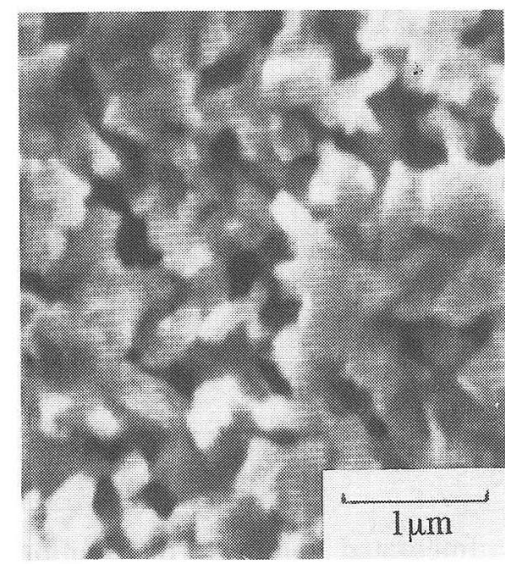

(c) $1473 \mathrm{~K}$

Fig.6. Morphological change of $\mathrm{TiN}_{\mathrm{CVD}}$ films with increasing annealing temperatures.

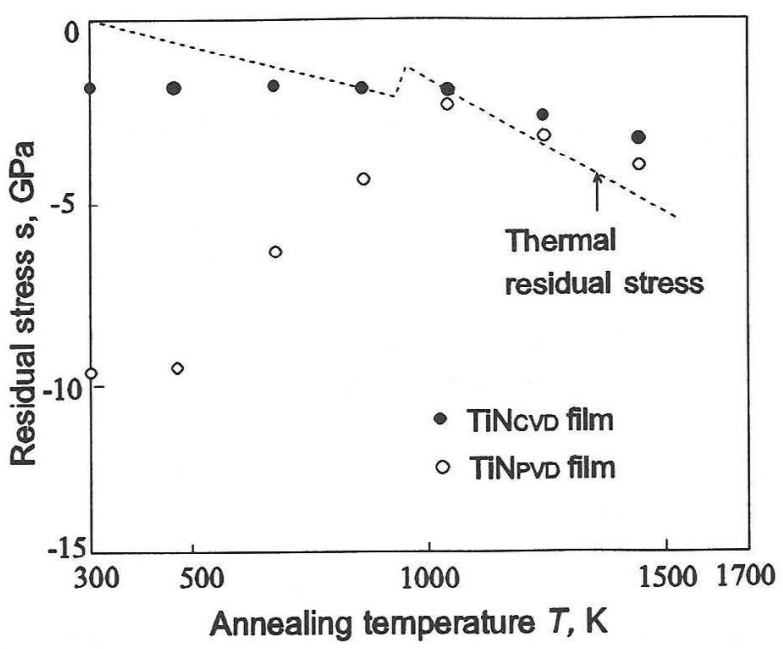

Fig.7. Changes in residual stress in the $\mathrm{TiN}_{\mathrm{CVD}}$ and the TiN $N_{P V D}$ film with increasing annealing temperatures.

obtained with increasing annealing temperature. The annealing treatment caused little increase in integrated intensity of the TiN films. The increase was so small that it is thought that the TiN crystals underwent no recrystallization. A relatively large decrease in the FWHM was obtained with increasing annealing treatment. As a result, a decrease in the third kind of residual stress or growth of TiN crystal grains occurred in the film.

The annealing treatment affects the surface condition of $\mathrm{TiN}_{\mathrm{CVD}}$ films. Scanning electron micrographs of the $\mathrm{TiN}_{\mathrm{CVD}}$ film surfaces are shown in Fig.6. Many small TiN crystal grains were observed on the TiN film surface. They show no significant change by annealing below $873 \mathrm{~K}$. Recrystallization of TiN grains appeared on the surface when the specimen was annealed at 1073 $\mathrm{K}$, which was higher than the deposited temperature (973 K). After annealing at $1473 \mathrm{~K}$, the growth of the recrystallized structure was observed in the film. As a result of this recrystallization, the surface roughness of the $\mathrm{TiN}_{\mathrm{CVD}}$ films was increased by crystal grain growth.

\subsection{Residual Stress}

Figure 7 shows the residual stresses measured in the $\mathrm{TiN}_{\mathrm{CVD}}$ film as well as in the $\mathrm{TiN}_{\mathrm{PVD}}$ film. Residual stress of the TiN film measured for five times. The thermal residual stresses calculated from the differences in the thermal contraction of the TiN film and the substrate [6] are also plotted.

The as-deposited $\mathrm{TiN}_{\mathrm{CVD}}$ and $\mathrm{TiN}_{\mathrm{PVD}}$ films have high compressive residual stresses of about -1.8 and -9.8 $\mathrm{GPa}$, respectively. We measured residual stresses five times. The range of the measured values was within $\pm 5 \%$ of the average value. The residual stresses in the $\mathrm{TiN}_{\mathrm{CVD}}$ films did not change after annealing at temperatures below $1073 \mathrm{~K}$. On the other hand, those in the TiN $_{P V D}$ films decreased along with increasing annealing temperatures above $473 \mathrm{~K}$, reaching the thermal residual stress level above $1073 \mathrm{~K}$. The compressive residual stresses in $\mathrm{TiN}_{C V D}$ and $\mathrm{TiN}_{\mathrm{PVD}}$ films increased by annealing above $1073 \mathrm{~K}$.

\section{DISCUSSION}

\subsection{Effect of Thermal Residual Stress}

The development of the residual stress in the film depends on the deposition conditions, such as temperature, ion bombardment (in PVD method) and environment. Mismatched thermal contraction between the film and the substrate generates thermal residual stress after cooling from the depositing temperature to room temperature. Assuming that there is no stress at the depositing temperature, the thermal residual stress is given by

$$
\sigma_{t h}=\frac{E_{F}}{1-v_{F}}\left\{\left(\alpha_{F}-\alpha_{s u b}\right) \Delta T+\Delta \varepsilon\right\},
$$

where $E_{F}$ and $v_{F}$ are, respectively, Young's modulus and 
Poisson's ratio of the film. $\alpha_{F}\left(\alpha_{F}=9.6 \times 10^{-6} \mathrm{~K}^{-1}\right)$ is the coefficient of thermal expansion (CTE) of the film. The $E_{F}, \nu_{F}$ and $\alpha_{F}$ values are assumed to be constant. When the substrate is carbon steel, the $\alpha_{\text {sub }}$ changes with temperature, and the volume changes owing to the phase transformation from austenite to ferrite. The cooling process of the substrate material is divided into three regions, i.e. (1) ferrite $\left(\alpha_{\text {sub }(1)}=13.9 \times 10^{-6} \mathrm{~K}^{-1}\right.$, below $950 \mathrm{~K})$, (2) transforming $\left(\Delta \varepsilon=1.54 \times 10^{-3}\right.$, between (1) and (3) ) and (3) austenite $\left(\alpha_{s u b(3)}=22.4 \times 10^{-6} \mathrm{~K}^{-1}\right.$, above $1000 \mathrm{~K})$ regions. From an expansion of Eq. (2), the thermal residual stress is represented [6]. And $\Delta T$ is the temperature drop from the depositing temperature to room temperature.

The as-deposited $\mathrm{TiN}_{\mathrm{CVD}}$ and $\mathrm{TiN}_{\mathrm{PVD}}$ films have high compressive residual stresses of about -1.8 and about $-9.8 \mathrm{GPa}$, respectively. The stress value in the $\mathrm{TiN}_{\mathrm{CVD}}$ was the same as the thermal residual stress (-1.6 GPa) calculated by Eq.(2) using $\Delta T=700 \mathrm{~K}$ which is derived from the depositing temperature of $973 \mathrm{~K}$. On the other hand, compressive residual stress in the TiN $_{\text {PVD }}$ film is one order larger than the thermal residual stress $(-0.57 \mathrm{GPa})$. High compressive stresses in the $\mathrm{TiN}_{\mathrm{PVD}}$ films seem to have been generated not only by the stress calculated by Eq.(2) but also by an ion bombardment of the film surface during the depositing process. However, the thermal CVD method has no effect on atomic peening during the depositing process because the films grow by chemical reaction in the heating chamber where the film and substrate temperatures are equal to the depositing temperature. It appears, therefore, the residual stress in the $\mathrm{TiN}_{\mathrm{CVD}}$ film originates solely from the thermal residual stress and can be calculated by the Eq.(2).

Residual stress in the $\mathrm{TiN}_{\mathrm{CVD}}$ film did not change by annealing up to $1073 \mathrm{~K}$, but increased along the thermal residual stress after annealing above 1073K. On the other hand, residual stress in the TiN $N_{P V D}$ film decreased with increasing annealing temperatures above $473 \mathrm{~K}$. After reaching the minimum value at $1073 \mathrm{~K}$, it increased with increasing annealing temperatures.

\subsection{The Relationship Between the Ratio of N/Ti and the Annealing Treatment}

Figure 8 shows the changes in the ratio of nitrogen to titanium $(\mathrm{N} / \mathrm{Ti})$ in $\mathrm{TiN}_{\mathrm{CVD}}$ and $\mathrm{TiN}$ PVD films. By $\mathrm{X}$-ray photoelectron spectroscopy (XPS), we determined the ratio $\mathrm{N} / \mathrm{Ti}$ after the annealing at various temperatures. The results of the XPS analysis showed that the initial value of $\mathrm{N} / \mathrm{Ti}$ was about 1.08 in as-deposited $\mathrm{TiN}_{\mathrm{CVD}}$ films. The ratio of $\mathrm{N} / \mathrm{Ti}$ did not change by annealing below $1073 \mathrm{~K}$, but it decreased to 1.00 by annealing above $1073 \mathrm{~K}$. On the other hand, the ratio of $\mathrm{N} / \mathrm{Ti}$ in the TiN $\mathrm{PVD}_{\mathrm{P}}$ films kept its initial value (1.08) until annealing up to $1273 \mathrm{~K}$, followed by a decrease to

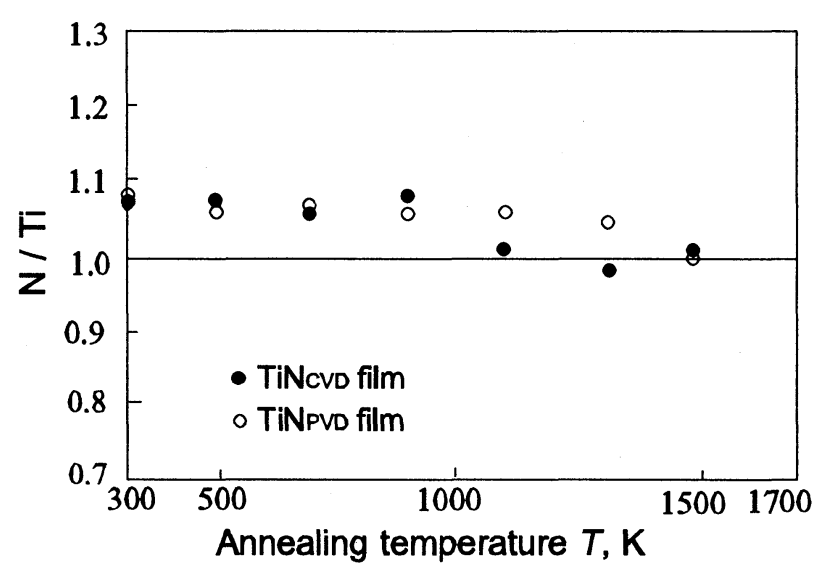

Fig.8. Changes in N/Ti ratio of the $\mathrm{TiN}_{\mathrm{CVD}}$ and the $\mathrm{TiN}_{\mathrm{PVD}}$ films with annealing treatments.

1.00 after annealing at $1473 \mathrm{~K}$. As a result, in the case of the $\mathrm{TiN}_{\mathrm{CVD}}$ films, as the Ti-N composition did not change after annealing below $1073 \mathrm{~K}$, residual stress in the $\mathrm{TiN}_{\mathrm{CVD}}$ films did not change after annealing below $1073 \mathrm{~K}$. On the other hand, the decrease of residual stresses in the TiN $N_{P V D}$ films after annealing below 1073 $\mathrm{K}$ was attributed to the relaxation of intrinsic stress generated by an ion bombardment during the depositing process, because the Ti-N composition in the $\mathrm{TiN}_{\mathrm{PVD}}$ films did not change after annealing below 1073K.

Compressive residual stresses in both $\mathrm{TiN}_{\mathrm{CVD}}$ and TiN $_{P V D}$ films increased by annealing above $1073 \mathrm{~K}$. These stresses are nearly equal to the thermal residual stresses but the slight difference between them increased with increasing annealing temperatures. This difference may have been caused by stress relaxation during annealing as a result of plastic deformation in the substrate near the interface and the change in Ti-N composition.

\section{CONCLUSIONS}

Residual stresses in the $\mathrm{TiN}_{\mathrm{CVD}}$ were measured by the X-ray two-exposure method. We investigated the residual stresses, Ti-N composition in the TiN film, and morphology of the film surface.

The $\mathrm{TiN}_{\mathrm{CVD}}$ film has a structure with very high $\{100\}$ orientation and compressive residual stress. The integrated intensity and FWHM did not change after annealing at temperatures below $1073 \mathrm{~K}$ but a large decrease in the integrated intensity and a large increase in the FWHM were observed after annealing at $1273 \mathrm{~K}$. Compressive residual stresses in the $\mathrm{TiN}_{\mathrm{PVD}}$ decreased with increasing annealing temperatures before reaching the minimum value at $1073 \mathrm{~K}$. Residual stresses in the $\mathrm{TiN}_{\mathrm{CVD}}$ films did not change after annealing at temperatures below $1073 \mathrm{~K}$. After annealing above $1073 \mathrm{~K}$, 


\section{Tatsuya MATsue, Takao Hanabusa and Yasukazu IkEUCHI}

residual stresses in the $\mathrm{TiN}_{\mathrm{CVD}}$ and also in the $\mathrm{TiN}_{\mathrm{PVD}}$ films began to increase to the compressive side along with the thermal residual stress but some differences existed between the measured stress and the thermal residual stress. Although the surface of the $\mathrm{TiN}_{\mathrm{CVD}}$ films showed no significant change by annealing below $873 \mathrm{~K}$, recrystallized TiN grains appeared on the surface when the specimen was annealed above $1073 \mathrm{~K}$, which is higher than the depositing temperature $(973 \mathrm{~K})$. The ratio of $\mathrm{N} / \mathrm{Ti}$ (TiN $\mathrm{TVD}_{\mathrm{CV}}$ and $\mathrm{TiN} \mathrm{N}_{\mathrm{PVD}}$ films) did not change by annealing below $1073 \mathrm{~K}$ but decreased to 1.00 after annealing above $1073 \mathrm{~K}$.

\section{REFERENCES}

1. A. J. Perry, M. Jagner, W. D. Sproul and P. J. Rudnich,
Surf. and Coat. Technol., 42 (1990) 49.

2. M. K. Hobbs, R. G. Cooke, B. Harris and H. Reiter, British Ceram. Proc., 39 (1989) 119.

3. G. C. Chang and W. Phucharoen, Surf. and Coat. Technol., 32 (1987) 307.

4. J. A. Sue, Surf. and Coat. Technol., 54-55 (1992) 154.

5. S. J. Bull, A. M. Jones and A. R. McCabe, Surf. and Coat. Technol., 54-55 (1992) 173.

6. T. Matsue, T. Hanabusa and Y. Ikeuchi, Thin Solid Films, 281-282 (1996) 344.

7. B. D. Cullity, Elements of X-Ray Diffraction, AddisonWesley Co. Inc., Massachusetts (1978) p. 75.

8. W.G. Sloof, B.J. Kooi, R. Delhez, Th.H.de Keijser, and E.J.Mittemeijer, J.Mater. Res., 11 (1996) 1440. 